\title{
THE BEHAVIOR CHART IN MENTAL DISEASES.
}

BY EDWARD J. KEMPF,

Assistant Resident Physician, Henry Phipps Psychiatric Clinic, Johns Hopkins Hospital, Baltimore, Md.

It is essential, if one wishes to understand the problem involved in any case of normal or abnormal behavior, to observe and record accurately the activities and ideas of the patient. This necessary work accumulates so rapidly that it often becomes difficult to retain the data and trends clearly in mind and keep them distinct from other cases. Frequently also the number of patients and other duties make it impossible to keep a satisfactory daily record of the behavior of each patient. Therefore, unfortunately, many interesting expressions, trends and attitudes are not recorded accurately in time, are even missed or their proper setting misunderstood, unless some special provision is made for observation and recording.

The purpose of the behavior chart described in this article is partly to fill this need, and to be added to the case record, but more so to extend research into the more fundamental, obscure and involved factors in behavior; to analyze and isolate such tendencies in behavior to which the human organism seems to give expression under similar circumstances, and which constitute the outlet for the emotional state. Perhaps such observations may add additional material, to find and understand and apply those fundamental biological principles, which psychiatry is so eagerly in search of at present.

With these several objects in view, it was found desirable to construct a chart upon which could be recorded the important variations in the patient's behavior, and which would give a graphic picture of the progress of the case. It seemed quite a simple problem at first, to construct a chart that would fulfill all the requirements, but several attempts soon revealed the difficulties involved. It was essential to have a style of chart that could be used for almost any type of a case, but it must not be too lengthy and complex. Also it should be comprehensive, and yet require 
observations that a trained nurse could make with a dependable degree of accuracy without permitting the observer to rely upon his own subjective imitations. Just as case histories and records vary with the observer, so will chart records tend to vary. Behavior is manifested in waves which tend more or less to vary in intensity or degree of deviation, and to vary in duration, type and continuity. A norm or mean is necessary for comparison, and it is placed to best advantage on the chart so that it will permit the recording of such acts which are characteristic for normals or desirable to be developed in abnormals, and are of the type that are usually intermediate between the excessively expanding and excessively contracting personality.

At the Kankakee, Illinois, State Hospital, a monthly chart with daily entries was devised and used principally for the purpose of recording the attendant's observation of the patient with regard to matters of care and occupation, and other matters of statistical interest. Later in I90I, at Worcester, Massachusetts, State Hospital, a similar chart was used, which was later revised and used in the New York State hospitals with this frame, and upon the further suggestions and encouragement of Prof. Adolf Meyer, the following behavior chart was completed and is now in use at the Phipps Clinic. While its form is not original, many of the essential features pertaining to the underlying biological principles of a behavior chart are extensively used here for perhaps the first time.

The satisfaction derived from the use of this type of chart depends upon the value of a graphic plot of the progress and behavior of the patient which may be added to a case history. The behavioristic value of the chart for the study of the psychosis depends very much upon one's interpretation of behavior, its physiology and psychology.

The biological principle involved in the chart is that a personality tends to expand and contract, to maintain a mean of expression, to extend its interests, psychic pseudopodia, into certain fields and to withdraw them from others, to enjoy outlets for expression and suffer inhibitions; and that for a like physiological-psychological state, this energy tends to express itself in a characteristiclike manner. For example, no matter how intelligent men may be, if enraged, they all tend to express themselves with characteristic behavior for that state. A word of explanation may be added 
here of what is meant by expanding-contracting (manic-depressive) behavior. An individual, for some to be explained reason, may be the host of a psychogenetic mechanism whereby he literally expands with energy. $\mathrm{He}$ is extremely active, the psychomotor apparatus is constantly at work, his fancies expand beyond all bounds, he is a king of immeasurable power and wealth, housed in a palace, where all his servants are princes and lords, etc. His mind is marvelously active and he lives a "million years in a minute." His physical powers are unlimited, etc. A week later everything may be changed to the opposite. He is in so intensively a contracted state, that he can only rub his hands and gaze anxiously, sadly, into space. He is " so weak" he "cannot move," he is a depraved, "worthless dog," a " sinner," " no good," " in the way," destitute and has " lost his soul " (libido). It would be impossible to plot a chart according to his exhilarated fancies or his hopeless pleas. But a chart may be plotted from the psychomotor expressions of such states, and a helpful inference drawn about the status of the individual's psychodynamic functions.

The author of the chart does not merely maintain that an individual has instincts to pick and rub himself, to be mute or to decorate himself with fæces, but rather holds that if an individual reaches a certain physiological-psychological state he will pick and rub himself, etc., the act being the expression and outlet of the underlying status. That is, to repeat, emotional states have characteristic outlets.

Such spontaneous expressions as are most usual or desirable for normal individuals were selected, arbitrarily arranged and placed in the central field of the chart to constitute the norm. From observations, of the behavior of numerous cases, a group of representatives acts, which indicate less than usual or no inhibition, were arranged in a series, and superimposed in such a manner that if they are checked off, as having been performed by the patient sometime during the day, the record will soon plot a curve the least inhibited acts being highest in the curve and farthest from the normal. To plot an opposite curve of excessive inhibition and contracture of the personality, data from the observation of cases were utilized and those states of excessiye inhibition and incoordination, as panic and incontinence, were placed in the series at the lowest extreme of the curve. 
A distinction is made between a field of spontaneous behavior and another of required behavior. The latter is selected principally to check off the patient's daily compliance with the special needs of the hospital. It is not arranged to plot a curve except for the appetite, where advantage is taken of the resistance of the patient and his indifference to food. The sleep curve is plotted I sq. $=\mathrm{I} \mathrm{hr}$. and is indicated by the irregular line running across the lower part of the chart.

The division named "spontaneous behavior" is the more important. The points required to be charted may not be the most satisfactory to be selected after further study and neither are they probably best arranged in the series, although the present selection and arrangement enables one to plot behavior quite graphically and faithfully.

Manic-depressive cases show an expanding-contracting type of behavior, which is manifested usually through generally characteristic-instinctive acts. Schizophrenic types are not quite so simple to chart, neither are the allied deteriorating types, paranoias, hysterias, and psychoneuroses. But if one includes a case record, any deviations of unusual behavior, whether manifested by a senile dementia or general paresis may be as profitably recorded as the picturesque variations of manic-depressive behavior.

The most important point to be observed in recording spontaneous behavior is the fact that it should be spontaneous. The estimation of a tendency or eccentricity of an individual cannot be well made unless the entire personality-the setting-is included. Such terms as "talks" are all used in a qualitative sense only. There is no reservation made for a quantitative eștimation of very talkative or slightly talkative, very restless, very irritable, or very impulsive or slightly resistant, for two reasons; because for one interpreter "very" may mean "moderate," and the second interpreter insist that the patient is only "slightly" and not "very" talkative. One sees such variations expressed by teachers about the intensity of a knee jerk. Secondly, if the patient, the psychodynamic machine, spontaneously speaks only once during the day, this important phenomenon must be noted as "talks," differing from the individual who is absolutely mute. The quantitative estimation can only be made from its setting, which is revealed by all the other possibilities which must be checked off 
if they occur. The psychomotor discharge through speech will not be the only expression of the psychodynamic status. The behavior of the entire psychomotor apparatus must be taken into account, and as such, a quite satisfactory plot of the patient's day may be recorded and estimated when one allows the various points to qualify one another.

Most of the words used in the chart are simple and self-explanatory. The terms within the norm need no explanation. The expansive group " restless," “ irritable," " impulsive," " resistant," " angry," "combative," are so placed because they occur more frequently with hypomanic and resentful patients. "Capricious" is used as quite a general term, and includes all such behavior as the dementia præcox case who says with a smile that he shouted to hear how it would sound, or the playful tricky pranks of a manic state. "Hoarding" is here used for that behavior which is usually a preparatory stage for the "creation" of odd, fanciful, original trifles, writings, designs, etc., and is used synonymously with accumulating. There is quite a jump to "flight of ideas" but compactness necessitates this. "Distractibility" would do well just preceding "flight of ideas" and "incoherent speech" could replace the latter, but the present arrangement seems practical. "Vulgarity" is usually the forerunner of poorly controlled eroticism of which "destructiveness," " masturbation," "exposure," being "careless with the discharge of excreta," and the extreme of " decorating with excreta " form a group. "Destructiveness" does not always accompany restrained eroticism. But when it does not, it is well qualified by other controlled expressions which would not be possible for a state of total lack of inhibition.

The depressed contracted states were more difficult to plot in a curve. "Disinterestedness" and the more shut-in state of "brooding" are quite self-explanatory and are checked off when the patient shows the difficulty of overcoming his spontaneous mental attitude of disinterestedness and brooding. The patient is not recorded as being "sad" unless he says he feels sad. He is recorded as "anxious" when he is uneasy and worried about some feature of his physical condition. This seems to occur more frequently in mild depressions and psychoneuroses and is usually not so grave as the next point, "apprehensiveness," which is used for a similar state of uneasiness and worry, but is referred 
to some cause in the environment, as being killed, cut up, enemies, danger, desertion, death of someone, etc. "Weeping" usually accompanies a state of more free, emotional expression than when the patient cannot "weep," but " picks and rubs" his skin, wrings his hands and paces the floor. Patients in this state often say weeping would give them relief if they could only do so. "Refuses to speak," " eyes closed," " motionless," " dressed by attendant," are grouped for the more profound states of inhibition found in depressions and catatonic states.

"Afraid" (or a general state of vague fear) seems to overlap " apprehensiveness," but is here used to include those states bordering on panickyness, for which there is no definite idea. "Afraid," "fears food" and "panicky" are so grouped to record degrees of feeling fear, which are always serious when they occur. "Fears food " always is associated with fears of being poisoned. "Incontinence " often accompanies profound depression and the paralysis of fear. It has no relation to the indifferent voiding of excreta by the manic or senile.

"Suicidal," "delusions" and "hallucinations" are placed at the foot of the division for spontaneous behavior, since they could not well be set in a curve and might occur in any picture.

The chart may be used for 24 -hour periods or less. It may frequently be useful to add a term for unusual peculiarities shown in some special case, such as dreams, convulsions, tics, hysterical vomiting, etc. If so, the point to be recorded is usually replaced for "delusions " or " suicidal."

For example, in the case of Mr. D. (dementia præcox), on the first and second of May his behavior was apparently normal. On the third he was somewhat restless, brooding, and anxious, which almost subsided on the fourth. But on the fifth the tension increased, showing his irritability, brooding, and the return of an old tendency to pick and rub (forehead). On the sixth it became more marked, and on the seventh he had an outburst of anger. The tension, however, continued despite the efforts to control himself, as shown by the points within the norm. On the IIth he had a more violent outburst of anger, and this was followed on the 12th by another outburst and a violent assault upon an attendant. The patient really was reacting with resentment toward his physician, but for some reason substituted for his attack the unsuspecting attendant. Here we see a gradual accumulation of resentment and a final outburst. The next day (13th), he regretted his actions, and the chart shows the marked inhibitions of self-censorship. He remained in his room, quiet, brooding, disinterested 
1915]

EDWARD J. KEMPF

767
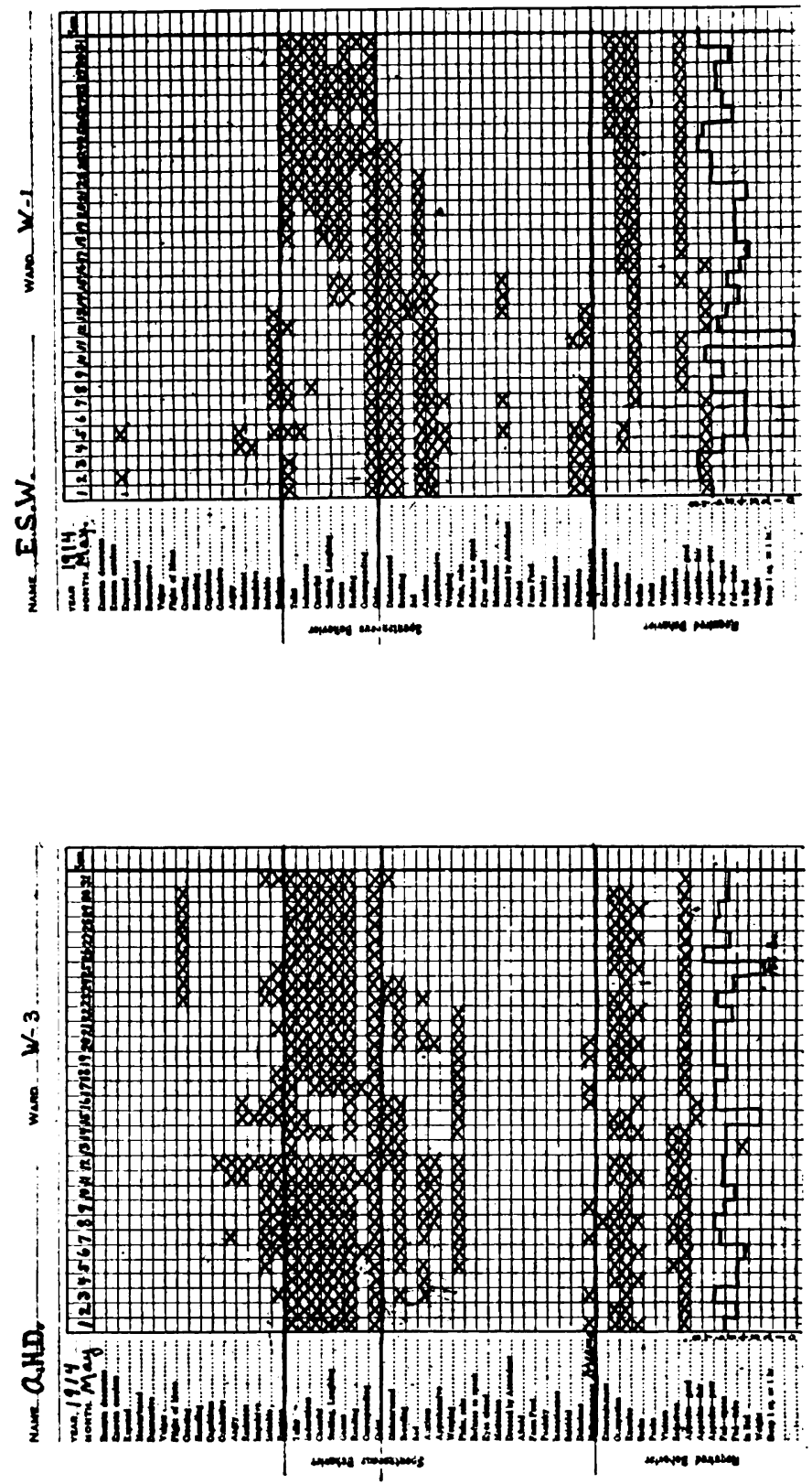
but somewhat talkative. On the $14^{\text {th }}$ this trend was resumed, and by the 15th he was again in his state of anger and protest. By the 23d his brooding and irritability had gradually subsided, and he entered into a state of hyperactivity, perhaps a type of self-display or creating in this instance, a Ryder Haggard type of novel, in which he plans to ridicule religion.

A talkative, industrious, smiling, individual, who will play games, may not be cheerful, but merely trying to cover what is, however, expressed in disguise in his creations and resentment, as in the case of the above patient.

The case of Mr. W., a state of hallucinatory depression, which existed for three months previous to admission, plotted the following curve:

At times he showed a negative type of resistance, refusing to comply with the nurses' requests. The patient had delusions of self-depreciation, impending punishment and destruction, with aural and visual hallucinations. He was very anxious about his kidneys and heart, and very apprehensive about the safety of his family. He believed they had deserted him, or that they were dead or dying, etc. Strangely enough he showed little tension, and never picked or rubbed himself. This status gradually disappeared, he became interested in games, read a little, began to talk, by the Ith he was smiling, and the next day seemed quite cheerful. By the $22 \mathrm{~d}$ he was industrious, and by the 25th had practically quit brooding about his sins. His expressions through June continued within the normal. The appetite and sleep curves showed interesting, quite parallel variations.

Mr. T., a case of manic-depressive insanity in a 19 year old boy. Shows a series of interesting upheavals of the manic type, but occasionally tinged with depressive tendencies at the same time. His upheaval had a sudden onset following a period of exhilaration of nine days and a conflict with a negro on February 27. For four weeks his inhibitions seemed to be at a very low stage. This state gradually subsided, although the tendency still showed in his capriciousness during the first two weeks in April. Suddenly, seemingly out of a blue sky, on the 16th of April, a second upheaval occurred. The cause was probably an attendant who secretly teased him. This second upheaval quickly subsided until the 5 th of May. The day previous his physician apparently aroused him through questioning him about his masturbation. The cause of the last upheaval was not learned. When this one subsided he determined to control himself, and succeeded quite well for the following two weeks, when he was removed by his people.

The sleep curve varied tremendously with his expansive-reactionary states, and decreased with the increase of his manic curve.

The chart shows how a tremendous wave of energy could not be inhibited or controlled, but expressed itself through a generally diffuse wave of psychomotor discharge and incoordination of thought.

Mr. C., a young man of 22, presented an interesting status which for several months could not be satisfactorily differentiated as a schizophrenic or manic depressive. He gave a questionable history of "feeling bad" for a year or more previous to the onset. This trend was relieved by a circumcision. In November, 1914, he presented a persistent difficulty to accommo- 

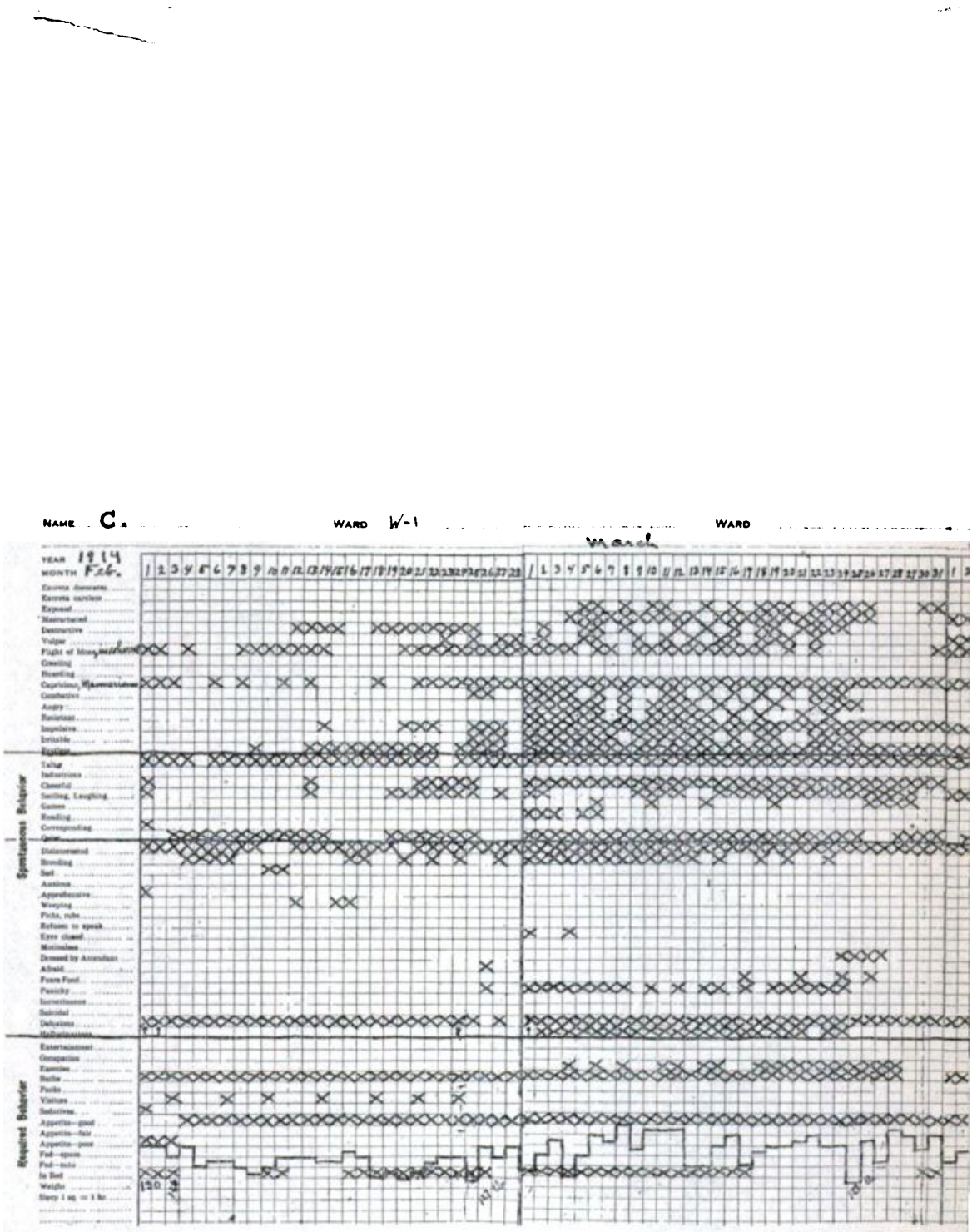


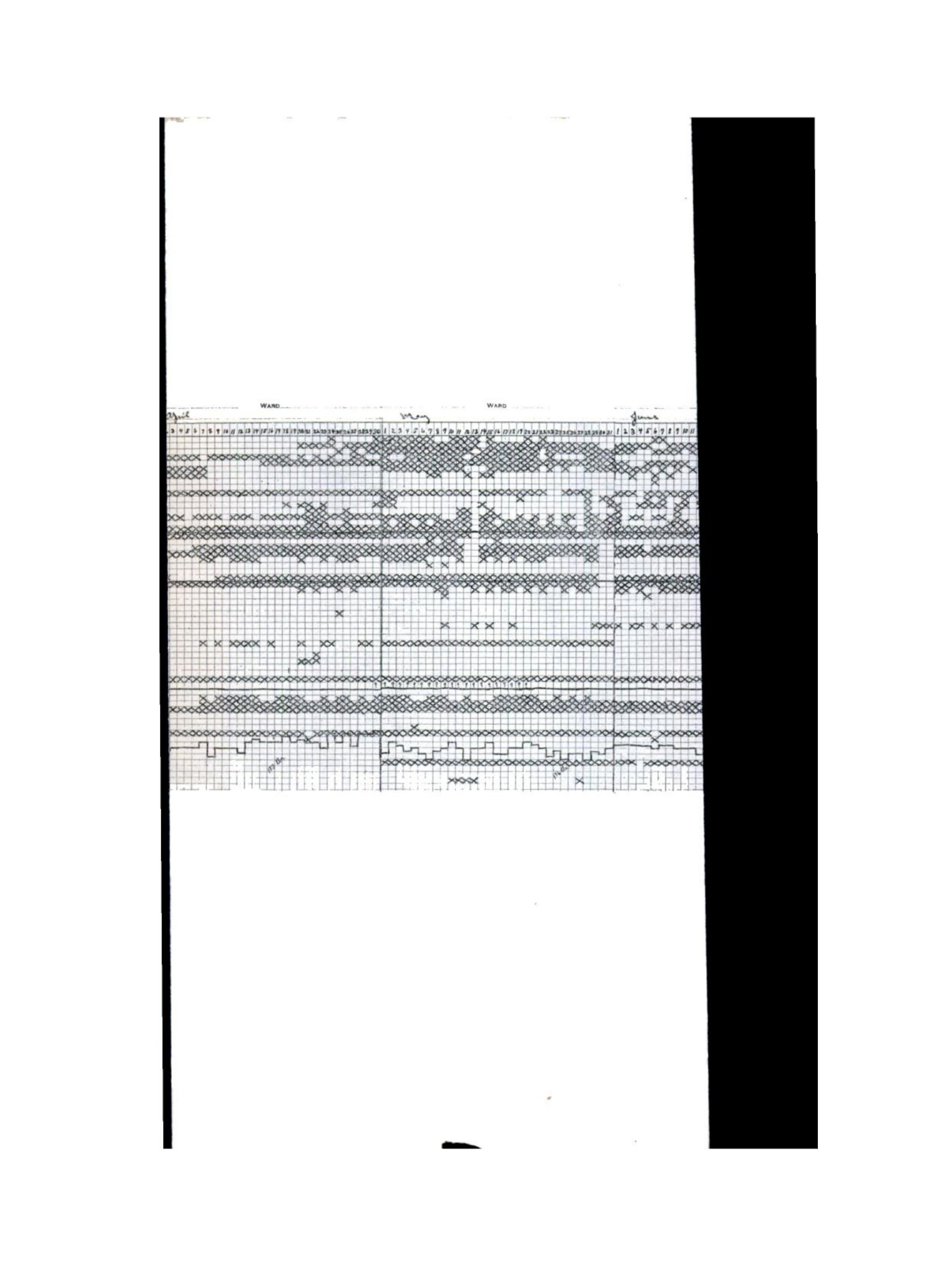



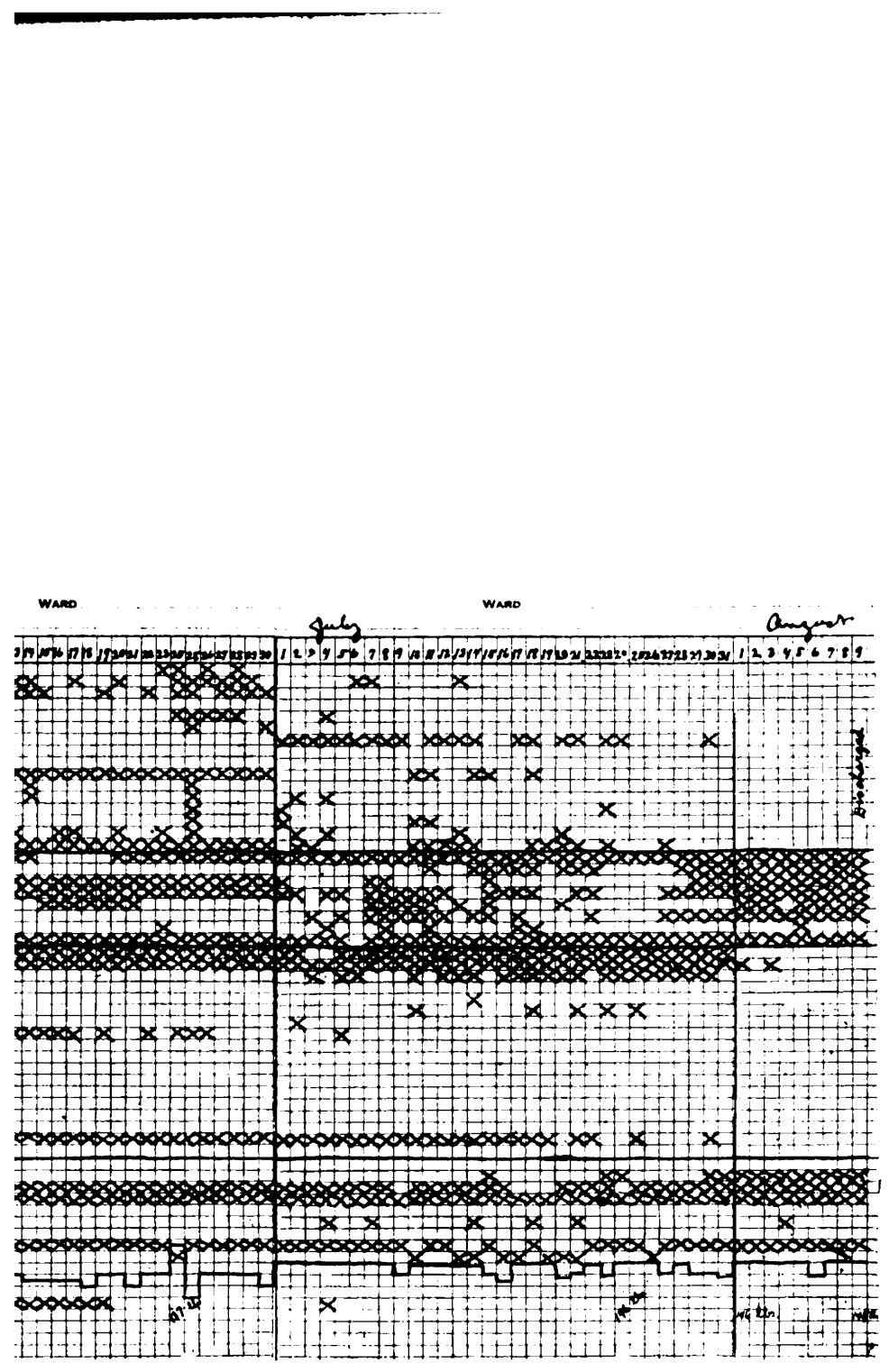


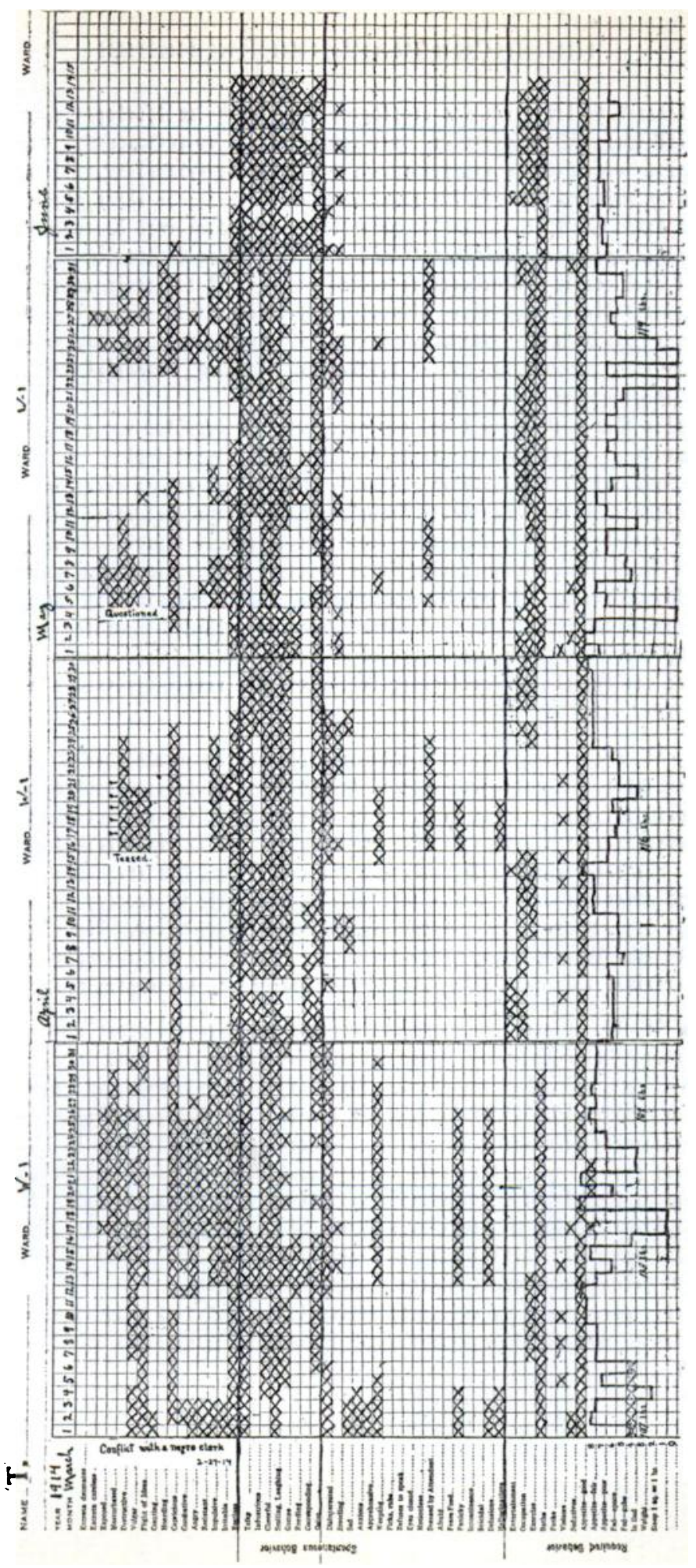


date himself to his work and employer. Gradually he developed suspicions and odd ideas of persecution. His reaction was an overactivity, tendency to elation, use of queer phrases which seemed to be symbolical, and yet were probably quite relevant to his troubles though slangy in their phraseology. About January 18 , he was no longer able to coordinate well or adapt himself to the quite precise requirements of his work. Then he developed auditory, visual and tactile hallucinations which he seemed to retain more or less throughout March and May; although this could not be positively affirmed. Much of his behavior was characterized by an uninhibited capriciousness, mannerisms, incoherent, rather symbolical thinking, resentfulness, and at times an unbridled eroticism.

During March this trend was very marked. It subsided somewhat during the middle of April and was most violent during the last of April, May and early June, when his behavior gradually changed to one of excessive inhibition, depression and uneasiness though curiously enough almost daily it was mixed with brief, little flights of capriciousness and impulsiveness. These trends finally disappeared and a quite normal readjustment was maintained until his discharge. The patient was never accessible enough to satisfactorily explain his symbolism and distinguish the material resulting from his schizophrenic tendency, and that of the manic-depressive reactions. The picture of the chart predominantly shows the manic-depressive type of behavior.

Mr. M., a case of dementia præcox, had already established a catatonic defense when this chart was started, but the type of defense and its unvarying persistence is recorded here. Only one month is shown, but it continued through a second month, when he was removed. This chart is self-explanatory. He entertained delusions and hallucinations, but they could not be elicited after his defense was well established. He is marked "talks" on certain days, because he spontaneously asked to go home. His fixed attitude of disinterestedness, brooding, sadness, anxiety and apprehensiveness characterized this catatonic defense and seemed to be impregnable.

Mr. W. M., a case of acute schizophrenia, shows a most unusual and regrettably brief behavior chart because of death. He was in a state of panic when admitted to the clinic. The chief topic elicited which seemed to have any bearing upon his mental state was his prolonged struggle against hoinosexuality and oral perversions. When he entered he was in a state of extreme fear of sexual assault, injury, and later of being murdered. He seemed to feel that he was unable to control himself any longer. He said he had been fighting this tendency all his life. His panic and struggles continued despite all efforts to control them, and he died on the seventh day in a state of profound exhaustion and vasomotor collapse.

In this case the state of acute schizophrenia plotted very interestingly, showing a marked disassociation of instinctive tendencies which usually regulate one another. 
I9I 5]

EDWARD J. KEMPF

771
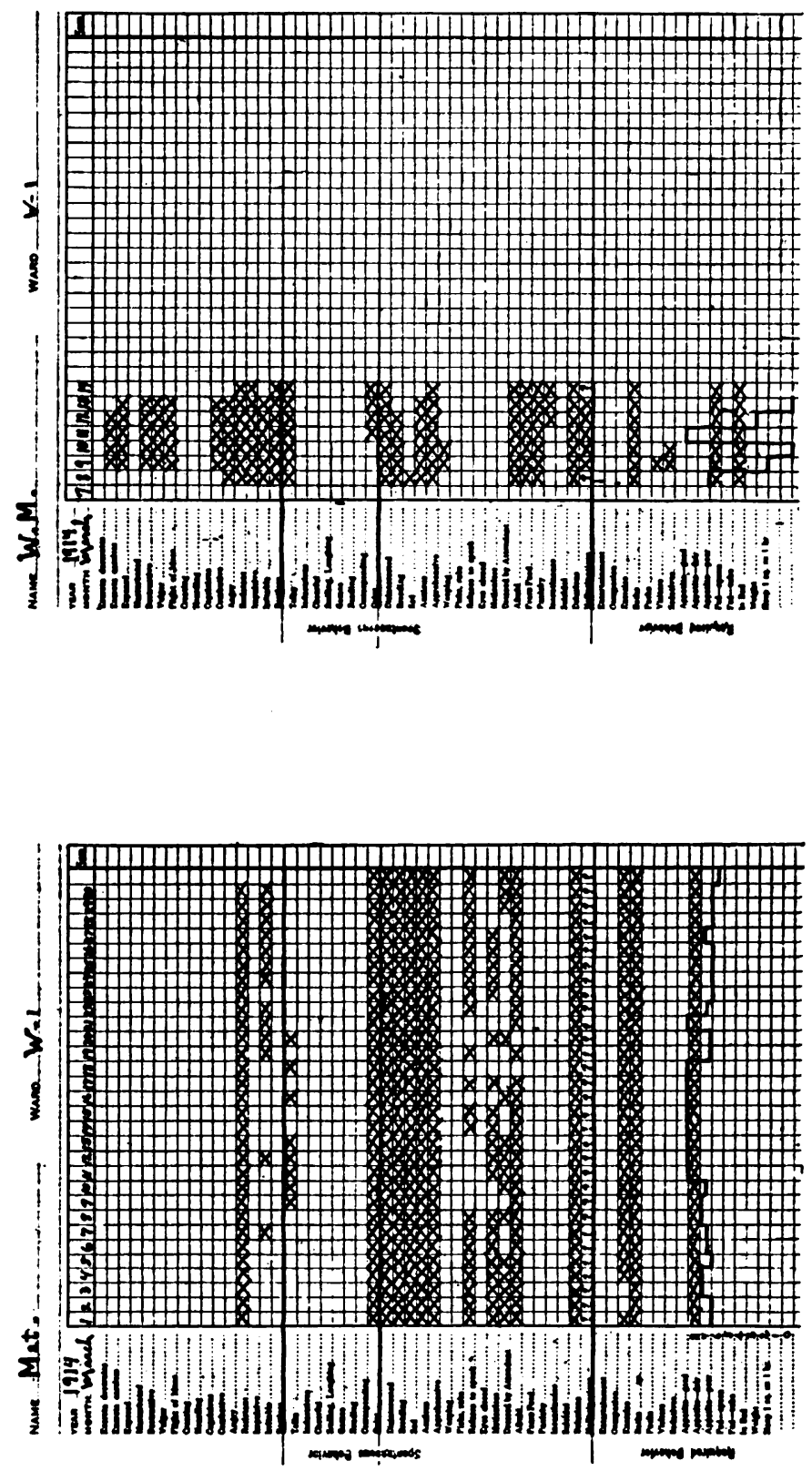
Conclusion.-The striking dissimilarity of the curves plotted for the various psychoses suggests that after further data are accumulated, suitable points isolated, and arranged in the most comprehensive series for the problems to be covered, perhaps a chart may be constructed which will aid materially in the classification of cases. Certainly the record of the case can only become more interesting and better clarified by an accurate chart record appended to the case history. Additional facts about behavior may also be gathered which will give us more insight into the more obscure biological principles determining behavior. 